\title{
Ein Jahrhundert in Werbeanzeigen
}

\author{
Wie Pharma- und Medtech-Produkte \\ in der Schweizerischen Ärztezeitung angepriesen wurden
}

1929

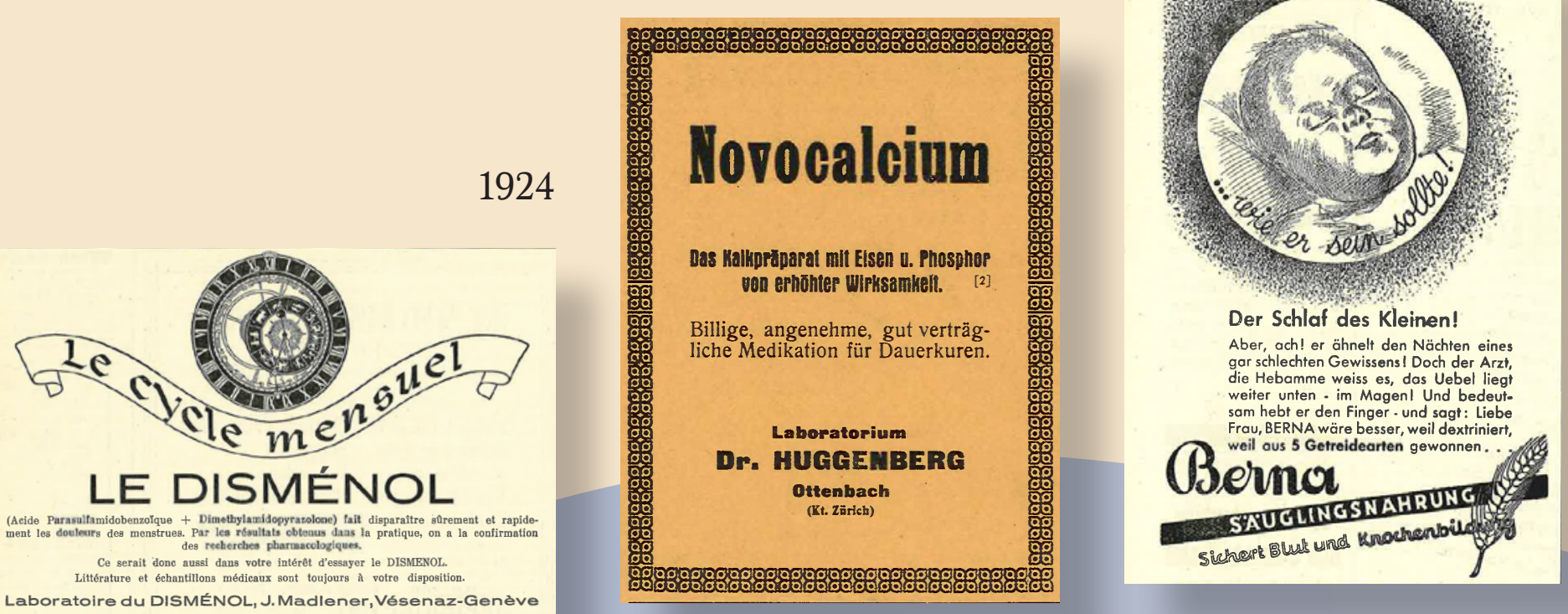

1929

1924

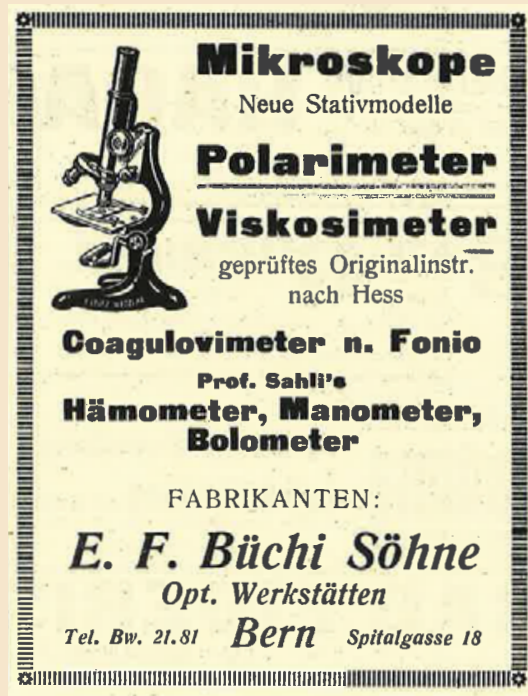



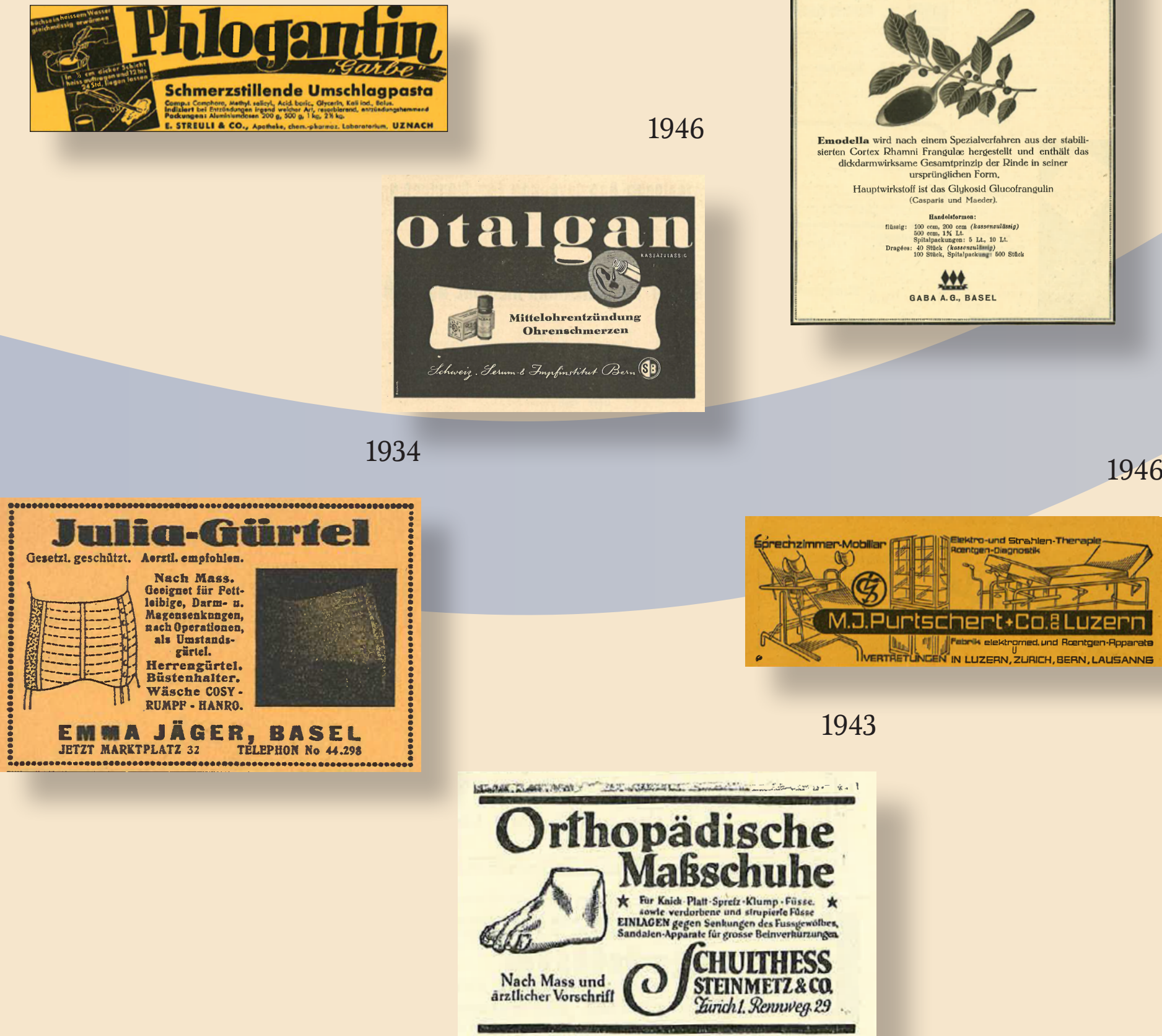


\section{7}

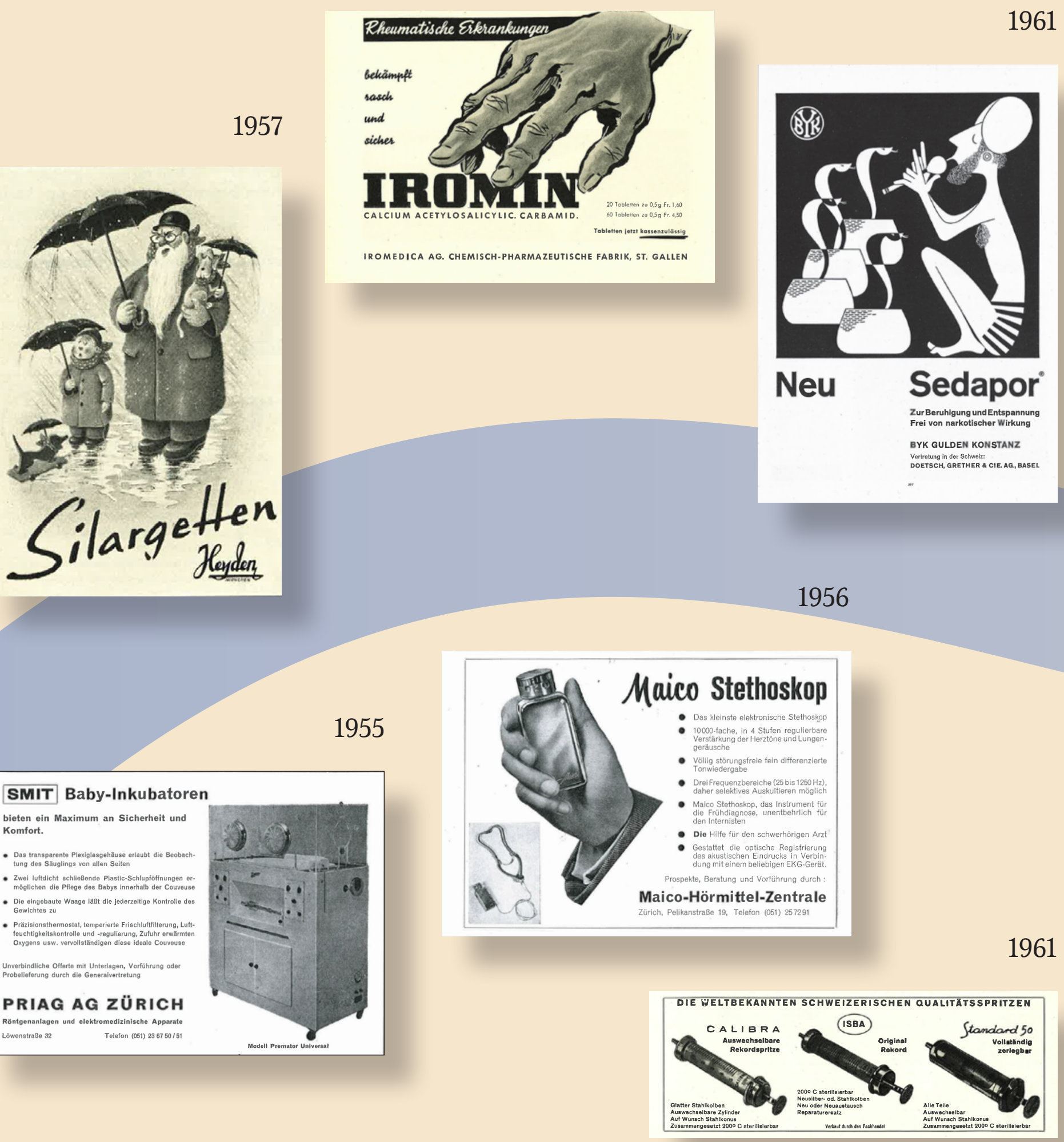

\{ 598\} 

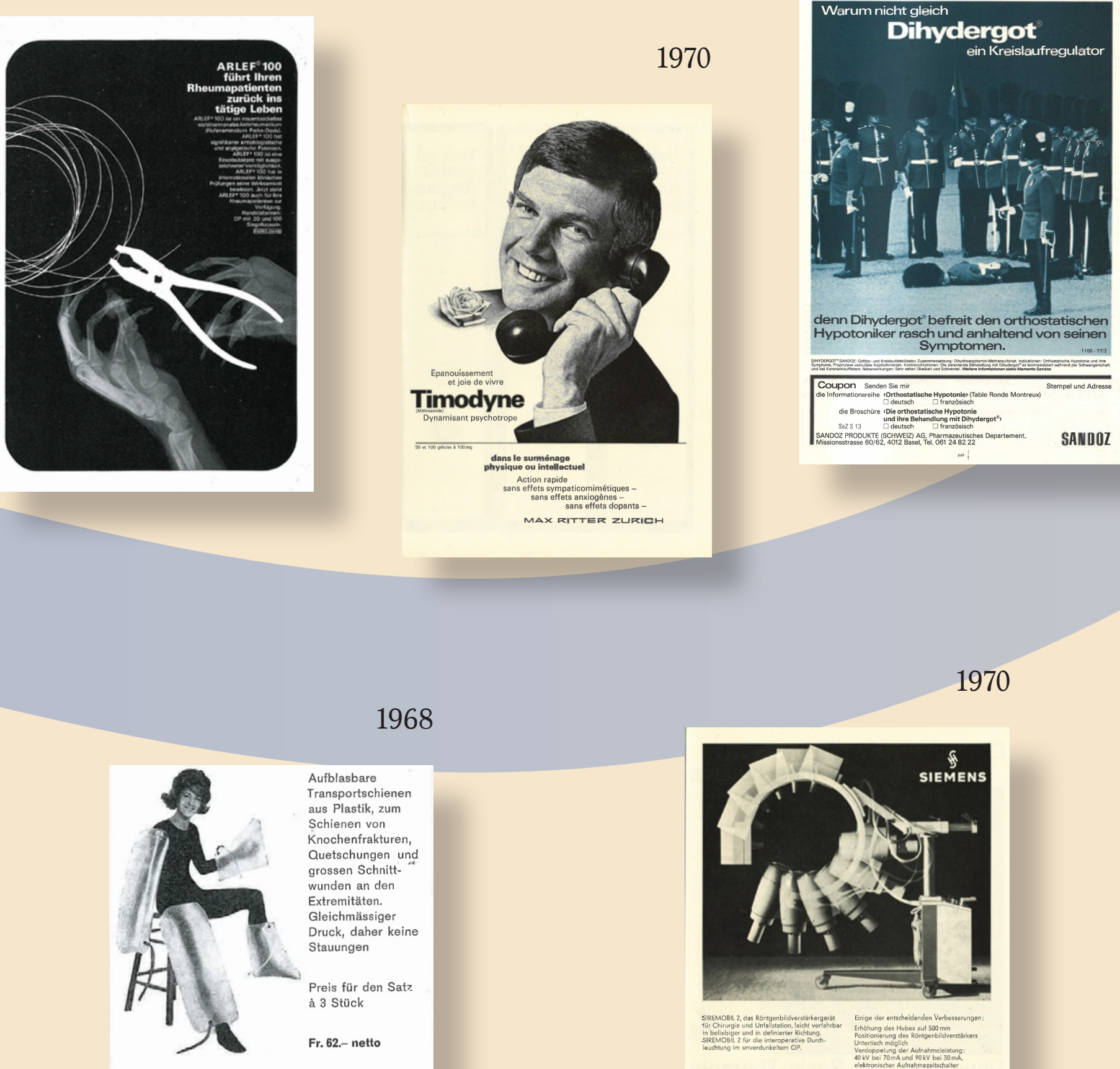

\section{Armin Roeschli}

\begin{tabular}{ll} 
Arzt- und Spitalbedarf & 8302 Augwil-Kloten \\
Verkauf und Service & Telefon 051 84 11 16 \\
(eigene Reparaturwerkstätte) & 3006 Bern \\
\hline & Telefon 031 4486 10
\end{tabular}

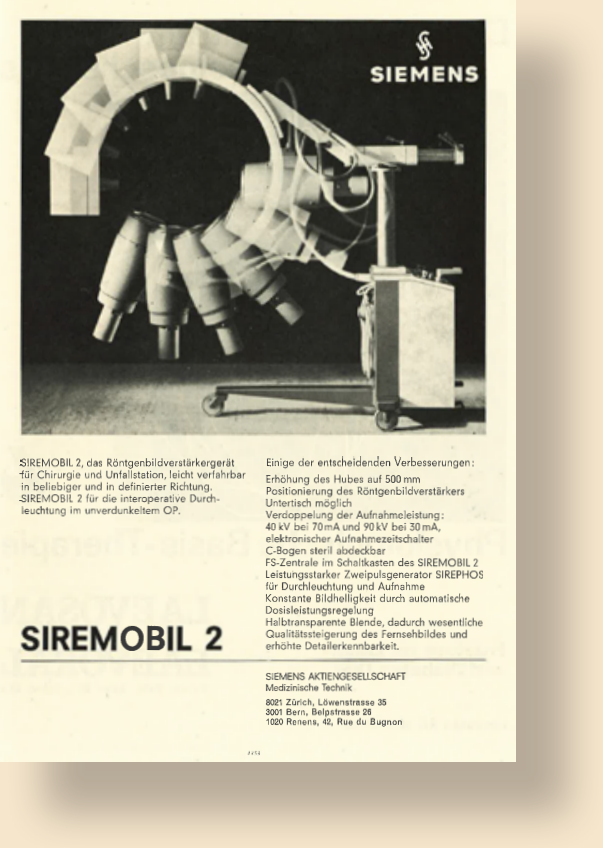



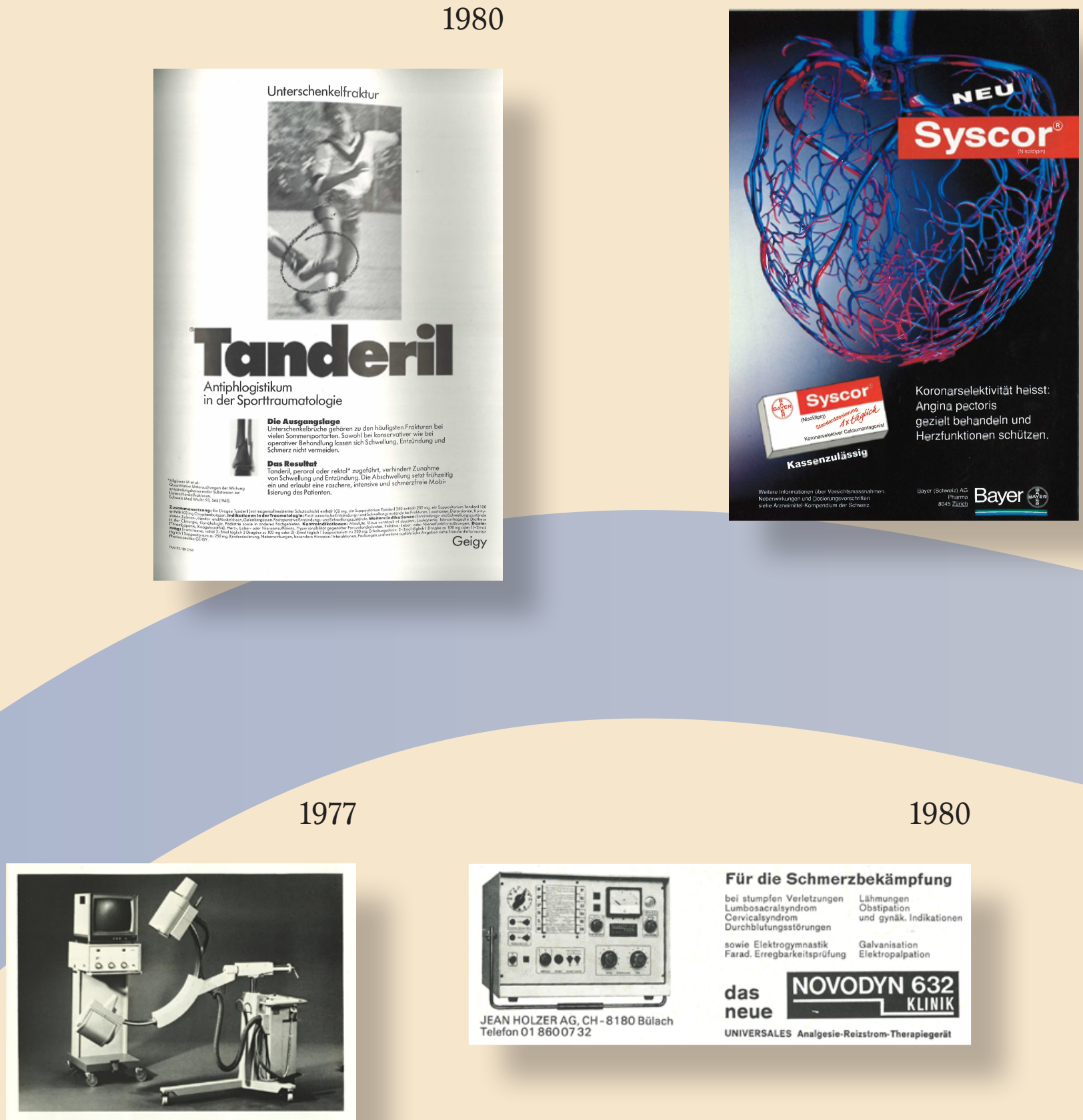

\section{Warum Chirurgen ein BV 22 von Philips wollen:}

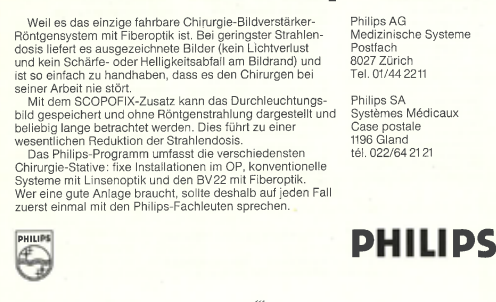

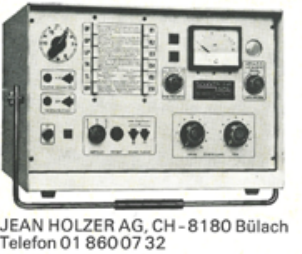

Für die Schmerzbekämpfung

bei stumpfon Veletzungen Lahmungen
Lumbosacralsyndrom

Corvicalsyndrom
Durchblutungstorungen und gynaki, Indikationen

sowio Elekktrogymnastik
Farad. Erregbarkeitspiófung Elisation
Fektropalpation

\section{das NOVODYN 632 \\ das}

neue - LLINIK 

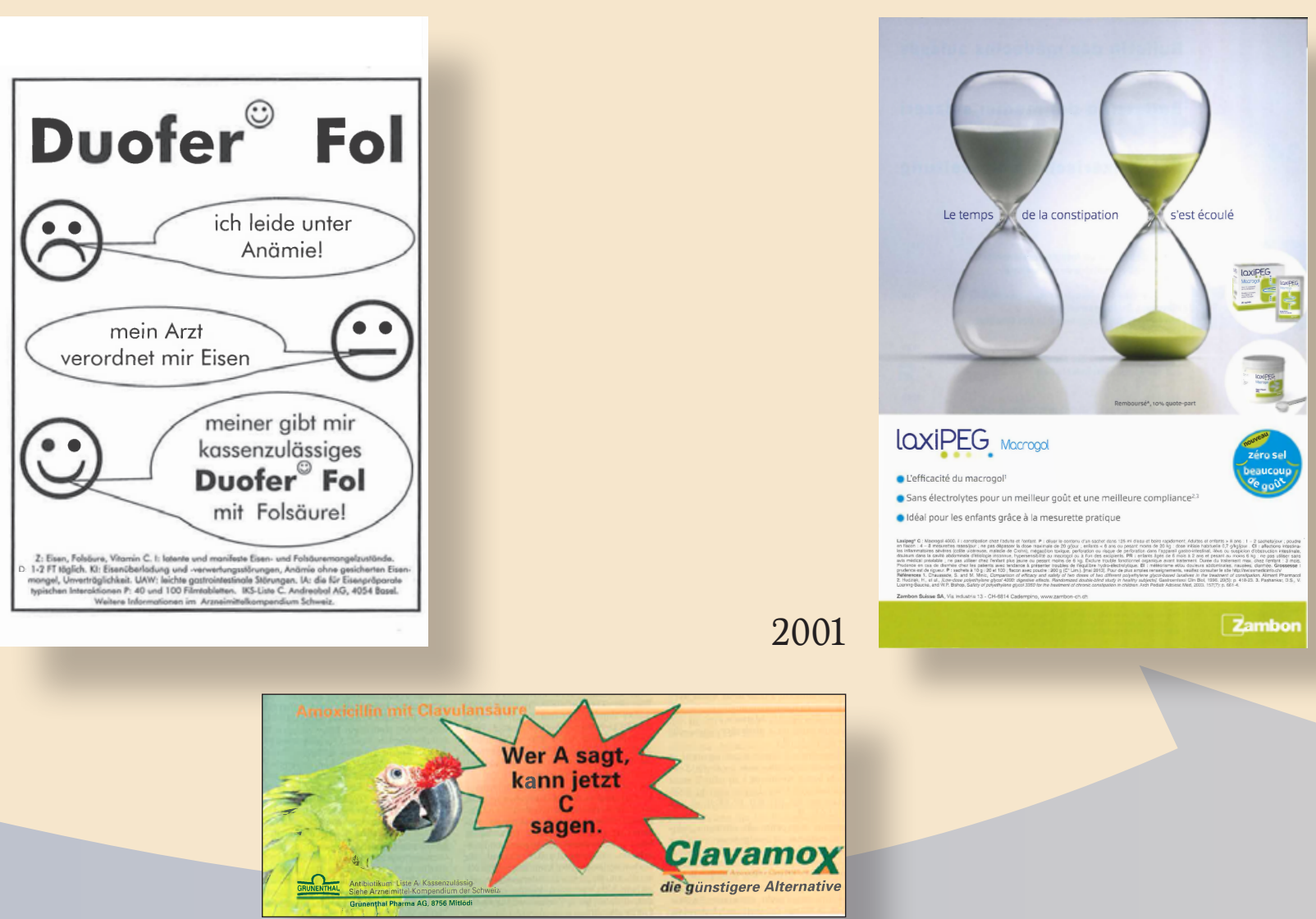

1992

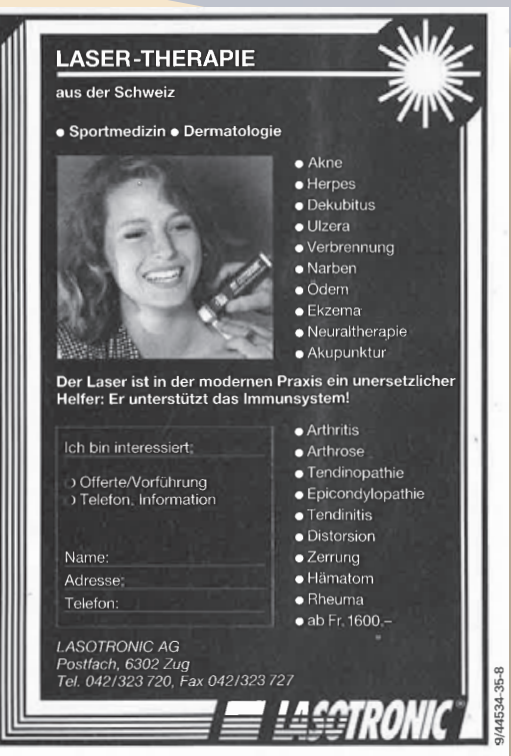

\section{8}

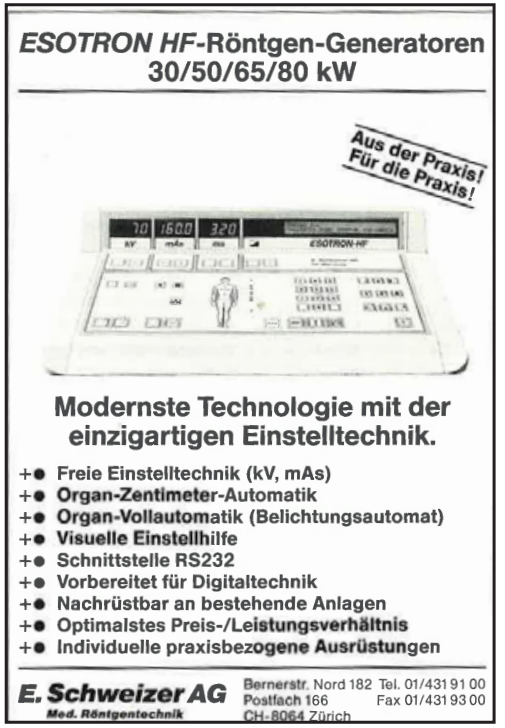

$\{601\}$ 